Oikos 118: 1695-1702, 2009

doi: $10.1111 / \mathrm{j} .1600-0706.2009 .17073 . x$,

(C) 2009 The Authors. Journal compilation (C) 2009 Oikos

Subject Editor: Jennifer Dunne. Accepted 29 May 2009

\title{
Using trophic hierarchy to understand food web structure
}

\author{
Marco Scotti, Cristina Bondavalli, Antonio Bodini and Stefano Allesina \\ M. Scotti (marcoscot@gmail.com), Center for Network Science, Central European Univ., Zrinyi u. 14, HU-1051, Budapest, Hungary. - MS, \\ C. Bondavalli, A. Bodini, Dept of Environmental Sciences, Univ. of Parma, Viale Usberti 11/A, IT-43100 Parma, Italy. - S. Allesina, \\ National Center for Ecological Analysis and Synthesis, 735 State Street, Suite 300, Santa Barbara, CA 93101, USA.
}

\begin{abstract}
Link arrangement in food webs is determined by the species' feeding habits. This work investigates whether food web topology is organized in a gradient of trophic positions from producers to consumers. To this end, we analyzed 26 food webs for which the consumption rate of each species was specified. We computed the trophic positions and the link densities of all species in the food webs. Link density measures how much each species contributes to the distribution of energy in the system. It is expressed as the number of links species establish with other nodes, weighted by their magnitude. We computed these two metrics using various formulations developed in the ecological network analysis framework. Results show a positive correlation between trophic position and link density across all the systems, regardless the specific formulas used to measure the two quantities. We performed the same analysis on the corresponding binary matrices (i.e. removing information about rates). In addition, we investigated the relation between trophic position and link density in: a) simulated binary webs with same connectance as the original ones; b) weighted webs with constant topology but randomized link strengths and c) weighted webs with constant connectance where both topology and link strengths are randomized. The correlation between the two indices attenuates, vanishes or becomes negative in the case of binary food webs and simulated data (weighted and unweighted).

According to our analysis, link density in food webs decreases with trophic position so that it is greatly reduced toward the top of the trophic hierarchy. This outcome, that seems to challenge previous conclusions based on null models, strongly depends on link quantification. Including interaction strengths may improve substantially our understanding of food web organization, and possibly contradict results based on the analysis of binary webs.
\end{abstract}

Food webs describe ecological communities as networks in which the species (nodes) are connected by directed links (arrows) representing energy transfers from resources to consumers. Understanding the structure of food webs, and in particular how feeding links are distributed among species, has received a lot of attention in recent ecological literature (Cohen et al. 1990, Williams and Martinez 2000, Cattin et al. 2004, Allesina et al. 2008). Links represent who eats whom in an ecosystem and consequently how species' feeding habits determine food web structure. Moreover, species' feeding activity defines their effective trophic level, representing a hierarchical organization of the food web (Christian and Luczkovich 1999). Given these premises, one interesting question is to study whether species connectivity relates to trophic position in a simple way.

The degree of connectivity exhibited by species in a food web is a key feature in food web analysis and has been measured in different ways, the most popular being the so called 'linkage density', defined as number of links per species (Cohen et al. 1990), also known as 'link density' (Bersier and Sugihara 1997) and the connectance, the fraction of realized links (Dunne et al. 2002a). All these measures are typically computed considering the sheer number of connections a species establishes in a food web. However, because the main function performed by feeding links is to deliver energy, the 'intensity' of connectivity should also be considered. To this end, we consider here a measure of link density, the average mutual information (Ulanowicz 2004), which takes into account the intensity and distribution of interaction strengths.

In the remainder of this work, we investigate the following questions: a) do species' link density correlate to species' trophic positions? b) can we detect general patterns for link density across ecosystems? c) do null-models predict same patterns than empirical food webs?

We analyzed 26 weighted food webs (Bersier et al. 2002) originally compiled as flow networks, models in which links between species express transfer of energy or matter from resources to consumers.

\section{Material and methods}

\section{Data}

We studied 26 quantitative food webs that were previously published as ecological flow networks. We gathered the data from two websites: eight networks were found in 
the ATLSS (across trophic level system simulation, $<$ www.cbl.umces.edu/ $\sim$ atlss/>) website and the other 18 models downloaded from Dr Ulanowicz's web page $(<$ www.cbl.umces.edu/ $\sim$ ulan/ $>$ ). The first dataset is composed of eight networks (four ecosystems, wet and dry season snapshots), while the second dataset is a more heterogeneous database including various ecosystems and different networks for same ecosystems (e.g. it includes six models of the Chesapeake Bay describing different geographical locations or seasons). A description of the 26 networks is provided in the Supplementary material Appendix 1 (Table S1). From these quantitative networks we obtained their binary counterpart by setting the magnitude of each link equal to 1 .

\section{Trophic position}

Ordering species in a community according to trophic positions yields a continuous trophic spectrum that defines a hierarchy from producers to consumers (van der Zanden et al. 1997, Bondavalli and Ulanowicz 1999). Conceptually, trophic position (TP) comes out from apportioning a species feeding activity to a series of discrete trophic levels sensu Lindeman (1942) and summing up these fractions. Its computation is made possible by a suite of different techniques that are essentially based on matrix manipulations; in this paper we used the following three methods: a) the canonical trophic aggregation (C, Ulanowicz and Kemp 1979, Scotti et al. 2006); b) the network unfolding approach (H, Higashi et al. 1989) and c) the path-based network unfolding algorithm (W, Whipple 1998). The main difference between the three methods lies in that in the $\mathrm{C}$ algorithm TP is computed using only trophic links; the other two make use also of non-trophic flows (i.e. detrital pathways; Ulanowicz and Kemp 1979, Higashi et al. 1989, Whipple and Patten 1993, Whipple 1998). In the $\mathrm{C}$ algorithm, TP is the weighted average length of all the loopless pathways from the primary source of energy to any species. Consider one species whose energy intake derives from primary producers $(20 \%)$ and from herbivores $(80 \%)$; the species is therefore $20 \%$ herbivore and $80 \%$ primary carnivore. Consequently, its TP is $0.2 \times 2+0.8 \times 3=2.8$. The integer numbers that appear in this calculation labels trophic levels and count exactly the number of steps energy travels to reach the species (primary producers have $\mathrm{TP}=1$, because they rely on solar energy and energy travels a pathway of length one: outside $\rightarrow$ primary producer. Herbivores are at level 2 because energy travels a pathway of length two: outside $\rightarrow$ primary producer $\rightarrow$ herbivore to reach them, and so forth). Diet fractions are apportioned to the corresponding trophic levels.

The idea of partitioning energy flows into portions belonging to different trophic levels is also shared by the other two methods. In the network unfolding scheme $(\mathrm{H})$, if a species $i$ is said to be an omnivore, partially behaving as herbivore and primary carnivore, its diet would comprise two parts, $i_{\mathrm{h}}$ and $\mathrm{i}_{\mathrm{c}}$ assigned at trophic level 2 and trophic level 3, respectively. An organism $j$ feeding on this species would thus receive an amount of energy from $i_{h}$ and another from $i_{c}$ so that it would be partially primary carnivore and partially secondary carnivore. By keeping track of these successive fractions throughout the web one can unfold the original networks in multiple linear trophic pathways, each one representing a particular chain of transfers that a unit of energy experiences in the ecosystem (Higashi et al. 1989).

Finally, the path-based network unfolding (W) is an extension of the previous method that deals with the problem of incrementing the trophic level also in presence of non-trophic flows ('trophic level inflation'; Whipple and Patten 1993). In essence, the original matrix-based method (Higashi et al. 1989) considers any passage of energy as incrementing the trophic level, with the receiving compartment always at a higher level than the donor, while the path-based method does not increase the trophic level in presence of non-trophic interactions which occur in the pathway such as, for example, egestive transfers from living to non-living compartments (Whipple 1998).

The main difference between the three methods is in the way they treat diet partitioning in ecosystems containing cycles, non-living matter storages (i.e. detrital components) and their accompanying non-trophic flows (i.e. decay, egestion, excretion).

\section{Average mutual information}

Average mutual information (AMI) expresses the average amount of constraints exerted upon an arbitrary unit of currency when passing from any one species to the next in an ecological network (Rutledge et al. 1976, Ulanowicz 1986). Both the number of links and their magnitude determine this measure. Figure 1 may help to understand this concept.

The upper left configuration (Fig. 1a) is said to be maximally constrained because there are no alternative a)

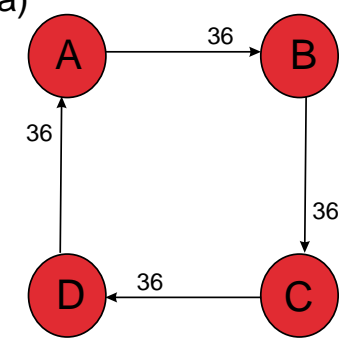

$\mathrm{AMI}=2$

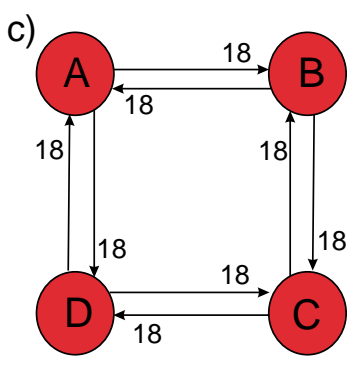

$\mathrm{AMI}=1$ b)

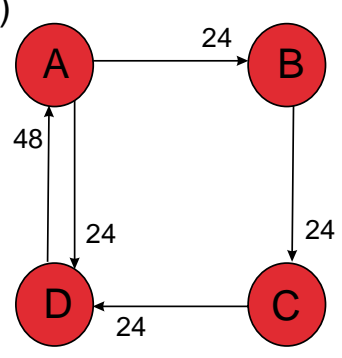

$\mathrm{AMI}=1.585$

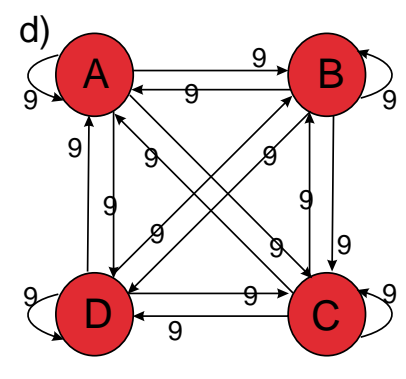

$\mathrm{AMI}=0$
Figure 1. Four hypothetical topologies for a network of four nodes: (a) maximally constrained (AMI maximized), (b) and (c) intermediate level of constraint, (d) most equivocal distribution of links (AMI $=0)$. Every node is at steady state and the total system throughput is preserved $(\mathrm{TST}=144)$. 
routes for the movement of a unit of matter, which thus moves in a completely predictable way. On the contrary, network 1d imposes less constraint to the 144 units of transfer among the four nodes and it is also the most equivocal configuration because in it the uncertainty about the fate of any single unit of transfer is maximized. According to the meaning of AMI and the way it is computed (details in Supplementary material Appendix 1), network 1a possesses the highest value of AMI whereas the lowest is for network $1 \mathrm{~d}$. The other two configurations represent intermediate situations between the two extremes.

AMI is usually computed as a whole system index; nevertheless it is possible to express the average amount of constraints also for single nodes (species) in a network. In that case AMI would measure the amount of constraints imposed to energy in the way it enters or exits any given node. Because these constraints are determined by the number and magnitude of its links, AMI becomes also a proxy for link density. For a single component AMI is similar to the Ulanowicz's effective connectance ( $m$ in Ulanowicz and Wolff 1991) and Bersier's link density (LD, in Bersier et al. 2002). Supplementary material Appendix 1 provides a brief comparative analysis of the indices. Suffice here to say that effective connectance and link density are computed by averaging the diversity of inputs and outputs for every node, whereas in our study we maintained the two contributions separated. In practice, for each node we calculated its AMI based on incoming links first, thus considering it as a predator, and then using outgoing links, viewing the node as a prey. We think this is more appropriate than computing AMI as the average contribution of incoming and outgoing links because TP classifies each species according to its feeding behavior, that is it considers its role as a consumer only.

We framed our analysis in two schemes. One, called 'AMI-living', in which computation of AMI was done using trophic links only (exchanges among non-detrital nodes); the second, called 'AMI-whole', in which this index included also the contribution of transfers from and to detritus. For further details see Fig. S1 (Supplementary material Appendix 1), in which we describe a typical matrix of ecological flow networks. The two schemes allow comparing the outcomes when indices are computed with and without non-trophic links.

\section{Statistical analysis}

For every single ecosystem we estimated the Spearman's correlation coefficients $(\rho)$ between TP and AMI. We decided for a non-parametric correlation because TP is not an independent variable (each species' TP depends on that of its prey), and both TP and AMI are not normally distributed, showing a narrow range of variation. The way we calculated TP and AMI allowed stressing different scenarios for the analysis. We considered the nodes in their role of prey (AMI based on outgoing links, Output scenario) and predators (AMI based on incoming links, Input scenario). For each scheme we compared 'AMI-living' and 'AMI-whole' with TP in all the forms we computed it: $\mathrm{C}, \mathrm{H}, \mathrm{W}$. In particular, we conceived different combinations for these indices: $\mathrm{C}$ vs 'AMI-living' only, and both $\mathrm{H}$ and W with 'AMI-whole'. These specific combinations reflect the coherence in the way indices are computed. So, it seemed reasonable to couple $\mathrm{C}$, which calculates species' trophic position on the base of trophic links only, with 'AMI-living' that also makes use of trophic links. On the other hand, both W and $\mathrm{H}$ compute species trophic position by including also non-trophic links; accordingly they have been associated with the 'AMI-whole' in the correlation analysis.

Trophic position and average mutual information were calculated also in simulated food webs. Over a total of 30000 null-graphs for each empirical food web used as a reference, 10000 were binary food webs with same connectance as the original one but with randomized link assignment. The other 20000 graphs were weighted food webs. Of these, 10000 preserved link topology as in the original webs and for the rest 10000 we maintained only the connectance and modified link arrangement. Link strengths in these models were assigned randomly within the range of magnitude shown by links in the original webs. Each node of these food webs was maintained at steady state applying a balancing procedure (Allesina and Bondavalli 2003). This minimized changes of link intensities in randomly assembled networks.

The Spearman's correlation coefficients for these models were estimated in the same 3 scenarios as explained before. Overall, we obtained nine correlation sets.

Scale dependence was also examined both graphically, plotting coefficients of correlation against the number of nodes, and performing a regression with the associated coefficient of determination $\left(\mathrm{R}^{2}\right)$.

\section{Results}

Table 1 summarizes the results of the statistical analysis performed on weighted food webs. A graphical synthesis is also provided by the box plots of Fig. 2a-b.

Under the Input scenario TP and AMI yielded a strong positive correlation, no matter which form was used for computing the two metrics. Only one coefficient was negative and not significant (final Narraganasett Bay model, when Higashi TPs are compared to 'AMI-whole' indices: $\rho=-0.123, p=0.503$ ). Most of the positive correlations were significant, although there were differences between the single correlations (Table 1, Fig. 2). With the index of trophic position estimated by $\mathrm{C}$ and AMI computed without the contribution of non-trophic links (Table 1, 1st column; Fig. 2a: C), the positive correlation was strong. Only for two ecosystems it was non-significant (Cedar Bog Lake and Ythan Estuary) and only the Lower Chesapeake (summer) showed a weak association $(\rho=0.453, p=0.011)$.

The other two indices of trophic position (Table 1, Input, columns $\mathrm{H}$ and $\mathrm{W}$ ) did not perform as well as $\mathrm{C}$ when compared to their AMI counterpart (with import, export and respiration flows entering the calculation). Non-significant correlations were still few, but the intensity of the association was less pronounced (Table 1, Input, columns $\mathrm{H}$ and $\mathrm{W})$.

Same analysis performed with AMI based on outgoing links produced the coefficients listed in Table 1 under the Output scenario. We obtained irregularly scattered points 
Table 1. Spearman's rho values (significance codes: $0 * * * 0.001 * * 0.01 * 0.05$ ) for the relationship between TP and AMI based on inflows (Input columns) or based on outflows (Output columns), when measured in the 26 real ecosystems described by weighted food webs: $\mathrm{C}=$ canonical trophic aggregation TP vs 'AMI-living'; $\mathrm{H}=$ original matrix-based TP vs 'AMI-whole'; W = path-based TP vs 'AMI-whole'. Total (S) and non-living $(\mathrm{nl})$ number of nodes are summarized.

\begin{tabular}{|c|c|c|c|c|c|c|c|c|}
\hline \multirow[b]{2}{*}{ Name } & \multirow[b]{2}{*}{$\mathrm{S}$} & \multirow[b]{2}{*}{$\mathrm{nl}$} & \multicolumn{3}{|c|}{ Input } & \multicolumn{3}{|c|}{ Output } \\
\hline & & & $\mathrm{C}$ & $\mathrm{H}$ & W & $\mathrm{C}$ & $\mathrm{H}$ & W \\
\hline Aggregated Baltic Sea & 15 & 3 & $0.808 * *$ & $0.771 * *$ & $0.764 * *$ & 0.295 & 0.070 & -0.118 \\
\hline Cedar Bog Lake & 9 & 1 & 0.591 & $0.681 *$ & $0.698 *$ & -0.482 & 0.170 & 0.186 \\
\hline Charca de Maspalomas & 21 & 3 & $0.750 * * *$ & 0.296 & 0.330 & -0.332 & $-0.513^{*}$ & $-0.558 * *$ \\
\hline Chesapeake mesohaline ecosystem & 15 & 3 & $0.758^{* *}$ & 0.309 & $0.617^{*}$ & $0.629 *$ & -0.302 & -0.007 \\
\hline Chesapeake mesohaline network & 36 & 3 & $0.894 * * *$ & $0.494 * *$ & $0.606^{* * *}$ & -0.228 & -0.134 & -0.167 \\
\hline Crystal River Creek (control) & 21 & 1 & $0.872 * * *$ & $0.864^{* * *}$ & $0.917^{* * *}$ & 0.207 & -0.110 & -0.092 \\
\hline Crystal River Creek (delta temp.) & 21 & 1 & $0.903 * * *$ & $0.756^{* * *}$ & $0.768^{* * *}$ & -0.277 & 0.145 & 0.111 \\
\hline Lower Chesapeake Bay (summer) & 34 & 3 & $0.453 *$ & $0.698^{* * *}$ & $0.758 * * *$ & -0.220 & $-0.393 *$ & $-0.425 *$ \\
\hline St Marks River flow network & 51 & 3 & $0.654 * * *$ & $0.413^{* *}$ & $0.508^{* * *}$ & -0.048 & $-0.325^{*}$ & $-0.364 * *$ \\
\hline Lake Michigan control network & 36 & 1 & $0.940 * * *$ & $0.875^{* * *}$ & $0.911^{* * *}$ & -0.092 & -0.176 & -0.122 \\
\hline Middle Chesapeake Bay (summer) & 34 & 3 & $0.772 * * *$ & $0.555^{* *}$ & $0.735 * * *$ & -0.269 & -0.323 & $-0.361 *$ \\
\hline Mondego estuary & 43 & 1 & $0.853^{* * *}$ & $0.733^{* * *}$ & $0.854 * * *$ & -0.086 & -0.070 & -0.040 \\
\hline Final Narraganasett bay model & 32 & 1 & $0.969 * * *$ & -0.123 & 0.002 & $0.416^{*}$ & -0.155 & -0.105 \\
\hline North Sea & 10 & 0 & $0.988^{* * *}$ & $0.948 * * *$ & $0.948^{* * *}$ & 0.348 & 0.243 & 0.243 \\
\hline Somme estuary & 9 & 1 & $0.753 *$ & 0.546 & 0.630 & -0.395 & 0.184 & 0.167 \\
\hline Upper Chesapeake Bay (summer) & 34 & 3 & $0.915 * * *$ & $0.365 *$ & $0.567 * * *$ & 0.085 & -0.234 & -0.302 \\
\hline Upper Chesapeake Bay & 12 & 2 & $0.899 * * *$ & $0.938^{* * *}$ & $0.915 * * *$ & 0.211 & 0.302 & 0.496 \\
\hline Ythan estuary & 13 & 3 & 0.618 & $0.741 * *$ & $0.863^{* * *}$ & -0.372 & -0.129 & -0.176 \\
\hline Cypress Wetlands (dry season) & 68 & 3 & $0.848^{* * *}$ & $0.845^{* * *}$ & $0.909 * * *$ & $0.248 *$ & $0.380 * *$ & $0.444^{* * *}$ \\
\hline Cypress Wetlands (wet season) & 68 & 3 & $0.831 * * *$ & $0.831^{* * *}$ & $0.888^{* * *}$ & 0.235 & $0.418^{* * *}$ & $0.488^{* * *}$ \\
\hline Marshes and sloughs (dry season) & 66 & 3 & $0.755^{* * *}$ & $0.572 * * *$ & $0.831^{* * *}$ & $0.374 * *$ & $-0.455^{* * *}$ & $-0.313 *$ \\
\hline Marshes and sloughs (wet season) & 66 & 3 & $0.716^{* * *}$ & $0.630^{* * *}$ & $0.895 * * *$ & $0.375^{* *}$ & $-0.471^{* * *}$ & $-0.307^{*}$ \\
\hline Florida Bay (dry season) & 125 & 3 & $0.913^{* * *}$ & $0.845^{* * *}$ & $0.905^{* * *}$ & $0.397 * * *$ & -0.083 & -0.022 \\
\hline Florida Bay (wet season) & 125 & 3 & $0.916^{* * *}$ & $0.796 * * *$ & $0.889 * * *$ & $0.391 * * *$ & -0.103 & -0.036 \\
\hline Mangroves (dry season) & 94 & 3 & $0.868^{* * *}$ & $0.648^{* * *}$ & $0.786 * * *$ & $0.251 *$ & $0.352 * *$ & $0.271 * *$ \\
\hline Mangroves (wet season) & 94 & 3 & $0.875 * * *$ & $0.671 * * *$ & $0.801 * * *$ & $0.252 *$ & $0.379 * * *$ & $0.289 * *$ \\
\hline Mean & & & 0.812 & 0.642 & 0.742 & 0.074 & -0.051 & -0.032 \\
\hline SD & & & 0.127 & 0.242 & 0.214 & 0.314 & 0.289 & 0.289 \\
\hline
\end{tabular}

(Fig. 2b), and the linear positive correlation observed before vanished. Most of the correlations, in fact, resulted not significant (50 out of 78 ), with average values close to 0 ; positive with TP based on trophic links only (Table 1, Output, column C) and slightly negative for the other two indices of trophic position (Table 1, Output, columns $\mathrm{H}$ and $\mathrm{W})$.

TP and AMI in binary food webs performed differently from their weighted counterparts (Table 2, Fig. 2c-d).

Overall, the correlation between AMI and TP tended to vanish in binary webs. In two cases the positive association between trophic position and link density was clear enough: those reported in $\mathrm{W}$ and $\mathrm{H}$ columns under the Input scenario in Table 2. These coefficients, however, were lower than the corresponding values in Table 1 . In the other cases average coefficients, either positive or negative, were close to zero, and no correlation emerged between trophic position and link density. In particular, the high correlation observed for weighted food webs in the Input scenario and column C (Table 1) completely vanished here, although few ecosystems showed the same behavior as when weighted (Charca de Maspalomas, Upper Chesapeake Bay). When indices were computed considering both trophic and non-trophic links, correlations remained positive, but lower than those found using weighted data (Table 2, Input, $\mathrm{H}$ and $\mathrm{W}$ columns). Under the Output scenario binary food webs displayed results similar to weighted food webs, with most negative coefficients of correlation.

To assess scale effect we analyzed Spearman's rho values in relation to the number of components $(S)$, measuring the coefficient of determination for distributions of AMI against TP, both in weighted and unweighted webs. The results of this analysis are summarized in Table 3 and visualized as six figures in the Supplementary material Appendix 1 (Fig. S2 for weighted networks and Fig. S3 for unweighted food webs). The relationship between AMI on ingoing flows and TP computed with the $\mathrm{C}$ algorithm, in binary food webs, was the only case in which results were affected by scale dependence $\left(\mathrm{R}^{2}=0.665, \mathrm{p}<<0.001\right)$.

Finally, Fig. 3 shows patterns observed for the same type of correlation using simulated food webs. In binary food webs with links randomly distributed, maintaining the connectance of real ecosystems used as a reference, the correlations became slightly negative (Fig. 3a). Preserving the topology of the ecosystems under investigation, varying link strength at random, made the correlations less strong (Fig. 3b). Randomizing link positions and intensities made the correlations vanish (Fig. 3c).

\section{Discussion}

Strong and significant correlations characterize the Input scenario in both weighted and unweighted food webs (Table 1, 2, Input columns). On the contrary AMI and TP did not correlate in the Output scenario (Table 1, 2, Output columns). This means that when the species are considered in their role of predators, a strong positive association between link density (AMI) and trophic position emerges. This association vanishes when AMI is 
a)

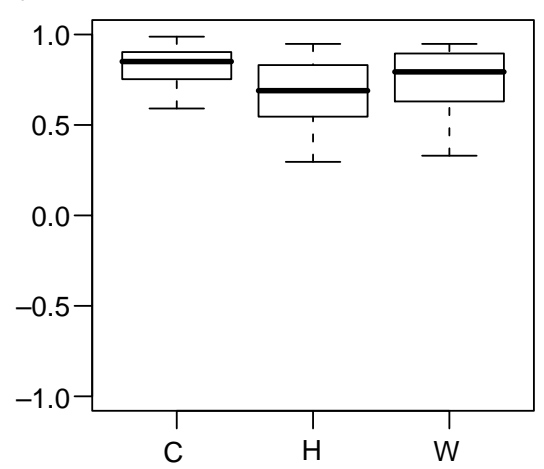

C)

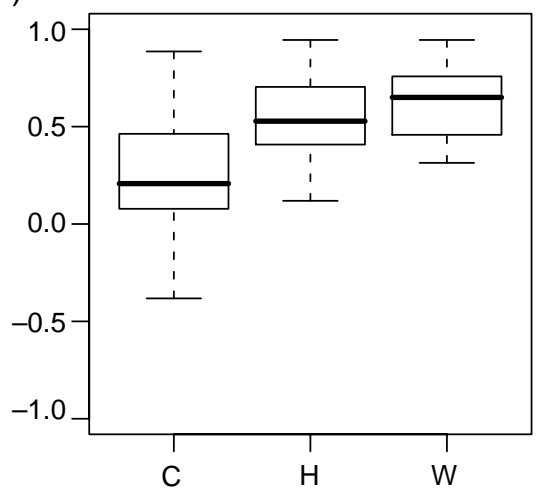

b)

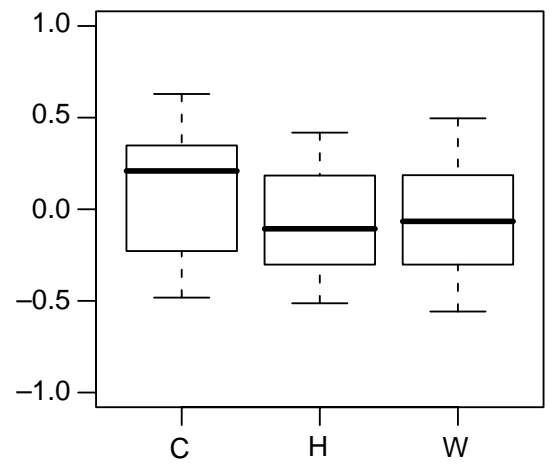

d)

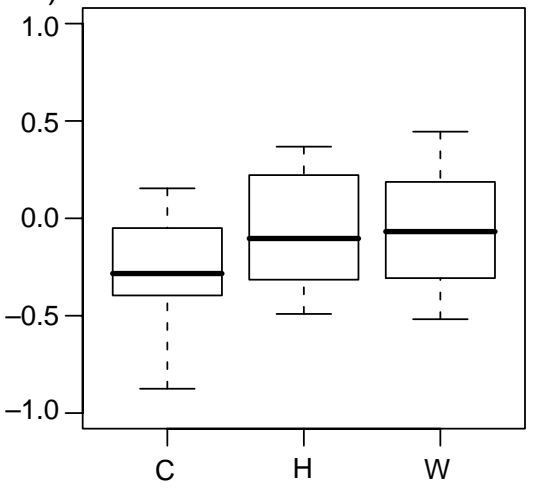

Figure 2. Box plots of correlation coefficients (Spearman's rho) for TP $(\mathrm{C}=$ canonical trophic aggregation; $\mathrm{H}=$ original matrix-based network unfolding method; $\mathrm{W}=$ path-based trophic unfolding method) vs AMI (on inflows left diagrams, on outflows right plots). Box plots in (a) and (b) refer to weighted food webs; crude binary information on link presence/absence yielded plots in (c) and (d).

computed using outgoing links, that is when species are seen as prey. The fewer links one node has and/or the skewer the distribution of their magnitude the higher the AMI is for that node. Thus, the positive correlation we observed between AMI and TP in the weighted food webs under the Input scenario tells us that links entering a node are fewer and/or total inflow more unevenly distributed among links for species that feed higher up in the food chain. According to this, species that occupy higher trophic positions tend to be specialized, while species at the bottom of the food web tend to be generalist. This pattern holds across ecosystems and is irrespective of the way one calculates the trophic positions, although some differences exist between these indices.

The asymmetry that emerges when link density is computed using consumer and resource connections deserves attention. In a previous study, Rossberg et al. (2006), while revisiting and extending what asserted by Holt and Lawton (1994), showed that species would differentiate their feeding preferences to avoid competition, so that foraging strategy rather than predatory avoidance would be the major determinant for food web structure. Herbivores would select primary producers to avoid competition with other herbivores, primary carnivores would select herbivores in the same way and so forth. Species would thus become "experts that consume families of experts". This pattern seems to be irrespective of what trophic position a species occupies. Our results are in accordance with Rossberg et al. in showing that link arrangement can be patterned according to species foraging strategies rather than some predatory avoidance behavior by the prey. However, the positive correlation we found between AMI and TP suggests species feeding higher in the trophic chain would resemble to the Rossberg's 'experts', and this 'expertise' would become less evident as we move toward the lower levels of the trophic hierarchy. Because we used link strengths explicitly, the "experts that consume families of experts" scheme could be forced by energetic constraints that might have produced the skewed distribution of experts toward the top of the trophic spectrum. Also, it is certainly possible that diet specialization may prevent top species from competition, but this cannot be inferred from our results.

Bersier and Kehrli (2008) analyzed the relationship between trophic and taxonomic similarity in food webs, and found that the trophic structure of the prey would be more related to phylogeny than that of predators; that is, taxonomically similar prey would tend to share taxonomically similar predators but these latter tend not to share taxonomically similar prey. From this evidence the authors argued that adaptation to avoid predators would be less important than adaptation to secure resources in structuring trophic interactions, a taxonomically based asymmetric behavior of the species in their role of predators and prey. We did not include taxonomic constraints in our investigation; however, as a preliminary exploration of a possible effect of taxonomic similarity on our outcomes, we isolated the values of TP and AMI for species belonging to 
Table 2. Coefficients of correlations (Spearman's rho) estimated for TP vs AMI on inflows (Input columns) or AMI on outflows (Output columns), when the 26 real ecosystems $(\mathrm{S}=$ total number of nodes, $\mathrm{nl}=$ non-living nodes) are represented as binary food webs: $\mathrm{C}=$ canonical trophic aggregation TP vs 'AMI-living'; $\mathrm{H}=$ original matrix-based TP vs 'AMI-whole'; $\mathrm{W}=$ path-based TP vs 'AMI-whole'.

\begin{tabular}{|c|c|c|c|c|c|c|c|c|}
\hline \multirow[b]{2}{*}{ Name } & \multirow[b]{2}{*}{$\mathrm{S}$} & \multirow[b]{2}{*}{$\mathrm{nl}$} & \multicolumn{3}{|c|}{ Input } & \multicolumn{3}{|c|}{ Output } \\
\hline & & & $\mathrm{C}$ & $\mathrm{H}$ & W & $\mathrm{C}$ & $\mathrm{H}$ & W \\
\hline Aggregated Baltic Sea & 15 & 3 & 0.467 & $0.746^{* *}$ & $0.758 * *$ & -0.152 & -0.002 & -0.059 \\
\hline Cedar Bog Lake & 9 & 1 & 0.544 & 0.443 & 0.658 & $-0.770 *$ & 0.237 & 0.221 \\
\hline Charca de Maspalomas & 21 & 3 & $0.745 * * *$ & 0.370 & 0.365 & $-0.540 *$ & $-0.491 *$ & $-0.516^{*}$ \\
\hline Chesapeake mesohaline ecosystem & 15 & 3 & $0.584 *$ & 0.147 & 0.314 & 0.154 & -0.379 & -0.307 \\
\hline Chesapeake mesohaline network & 36 & 3 & $0.438 *$ & $0.367 *$ & $0.444 * *$ & $-0.463 * *$ & -0.166 & -0.146 \\
\hline Crystal River Creek (control) & 21 & 1 & 0.135 & 0.432 & $0.563 * *$ & 0.050 & -0.142 & -0.209 \\
\hline Crystal River Creek (delta temp.) & 21 & 1 & $0.449 *$ & 0.255 & 0.381 & -0.291 & 0.204 & 0.144 \\
\hline Lower Chesapeake Bay (summer) & 34 & 3 & 0.187 & $0.557 * *$ & $0.699 * * *$ & $-0.362 *$ & $-0.471 * *$ & $-0.518^{* *}$ \\
\hline St Marks River flow network & 51 & 3 & 0.173 & $0.408^{* *}$ & $0.424 * *$ & -0.191 & -0.146 & -0.261 \\
\hline Lake Michigan control network & 36 & 1 & 0.195 & $0.596 * * *$ & $0.725^{* * *}$ & -0.278 & -0.108 & -0.129 \\
\hline Middle Chesapeake Bay (summer) & 34 & 3 & $0.361 *$ & $0.358 *$ & $0.458 * *$ & $-0.396 *$ & $-0.396^{*}$ & $-0.425^{*}$ \\
\hline Mondego estuary & 43 & 1 & 0.220 & $0.458 * *$ & $0.712 * * *$ & $-0.459 * *$ & 0.034 & -0.044 \\
\hline Final Narraganasett bay model & 32 & 1 & 0.103 & 0.119 & $0.394 *$ & -0.217 & -0.170 & -0.078 \\
\hline North Sea & 10 & 0 & 0.329 & $0.945^{* * *}$ & $0.945 * * *$ & -0.298 & 0.250 & 0.250 \\
\hline Somme estuary & 9 & 1 & 0.236 & 0.563 & $0.726^{*}$ & $-0.875^{* *}$ & 0.368 & 0.244 \\
\hline Upper Chesapeake Bay (summer) & 34 & 3 & $0.463 * *$ & $0.576^{* * *}$ & $0.642^{* * *}$ & -0.288 & -0.315 & $-0.363^{*}$ \\
\hline Upper Chesapeake Bay & 12 & 2 & $0.886^{* *}$ & $0.887^{* * *}$ & $0.924 * * *$ & 0.088 & 0.206 & 0.445 \\
\hline Ythan Estuary & 13 & 3 & 0.472 & $0.704 * *$ & $0.848^{* * *}$ & $-0.706 *$ & -0.011 & -0.028 \\
\hline Cypress Wetlands (dry season) & 68 & 3 & 0.111 & $0.775^{* * *}$ & $0.792 * * *$ & $-0.367^{* *}$ & $0.334 * *$ & $0.329 * *$ \\
\hline Cypress Wetlands (wet season) & 68 & 3 & 0.078 & $0.652 * * *$ & $0.673^{* * *}$ & $-0.364 * *$ & $0.330 * *$ & $0.333 * *$ \\
\hline Marshes and Sloughs (dry season) & 66 & 3 & -0.151 & $0.482 * * *$ & $0.625 * * *$ & 0.099 & $-0.465^{* * *}$ & $-0.450 * * *$ \\
\hline Marshes and sloughs (wet season) & 66 & 3 & -0.150 & $0.515^{* * *}$ & $0.640^{* * *}$ & 0.093 & $-0.445^{* * *}$ & $-0.412 * *$ \\
\hline Florida Bay (dry season) & 125 & 3 & -0.168 & $0.839 * * *$ & $0.894^{* * *}$ & -0.050 & -0.106 & -0.065 \\
\hline Florida Bay (wet season) & 125 & 3 & -0.154 & $0.829 * * *$ & $0.886^{* * *}$ & -0.040 & -0.101 & -0.071 \\
\hline Mangroves (dry season) & 94 & 3 & $-0.382 * *$ & $0.531 * * *$ & $0.612 * * *$ & $-0.272 * *$ & $0.222 *$ & 0.162 \\
\hline Mangroves (wet season) & 94 & 3 & $-0.380^{* *}$ & $0.525^{* * *}$ & $0.602 * * *$ & $-0.279^{* *}$ & $0.239 *$ & 0.187 \\
\hline Mean & & & 0.223 & 0.541 & 0.642 & -0.276 & -0.057 & -0.068 \\
\hline SD & & & 0.323 & 0.215 & 0.183 & 0.268 & 0.282 & 0.285 \\
\hline
\end{tabular}

extremely coarse taxonomic groups, in particular fish and bird species, as we could not provide a finer taxonomic classification, and calculated the correlations between the two indices. We are not reporting these results here, as our approach needs to be framed in a more taxonomically rigorous one; however, we found that these two groups exactly reproduced the pattern we observed in the whole food webs: strong positive correlation between the two metrics in the Input scenario and no relationships between TP and AMI in the Output scenario. So, it seems that taxonomic similarity does not affect the pattern of link arrangement as a function of TP.

Under the Input scenario results suggest other consid-

Table 3. Coefficients of determination for scale dependence of the Spearman's rho values. Each row in the table refers to a particular type of comparison between AMI and TP as described in the text. Keys are: for $\mathrm{TP}, \mathrm{C}=$ canonical trophic aggregation; $\mathrm{H}=$ original matrix-based network unfolding; $\mathrm{W}=$ path-based trophic unfolding and for AMI, IN = based on incoming flows; and OUT = based on outgoing flows. Results are for both weighted and unweighted food webs.

\begin{tabular}{lccllr}
\hline & \multicolumn{2}{c}{ Weighted } & & \multicolumn{2}{c}{ Unweighted } \\
\cline { 2 - 3 } \cline { 6 - 6 } & $\mathrm{R}^{2}$ & $\mathrm{p}$ & & \multicolumn{1}{c}{$\mathrm{R}^{2}$} & $\mathrm{p}$ \\
\hline C - AMI IN & 0.060 & 0.229 & & 0.665 & $<<0.001$ \\
H - AMI IN & 0.025 & 0.436 & & 0.074 & 0.179 \\
W - AMI IN & 0.069 & 0.193 & & 0.050 & 0.273 \\
C - AMI OUT & 0.210 & 0.019 & & 0.109 & 0.099 \\
H - AMI OUT & 0.009 & 0.643 & & 0.0001 & 0.958 \\
W - AMI OUT & 0.014 & 0.569 & & 0.0003 & 0.935 \\
\hline
\end{tabular}

erations. First, the correlation of AMI and TP when based only on trophic links yielded different outcomes for weighted and unweighted food webs. These latter showed no correlation between AMI and TP, and, for certain ecosystems, the correlation turned negative (Table 2, column C). Upon including non-trophic links the two indices showed a positive correlation in both weighted and unweighted food webs, with lower values for the latter (Table 2, columns $\mathrm{H}$ and $\mathrm{W}$ ). This is not surprising if one considers that non-trophic links point to species that occupy lower trophic position (i.e. recycling does not involve top predators) and this increases disproportionately the number of connections at the bottom of trophic spectrum.

Since most of the literature on food webs deals with networks comprised of trophic links only, our results should be discussed in this framework, that is emphasis must be given to the comparisons between $\mathrm{C}$ and 'AMI-living'.

The absence of correlation between AMI and TP when the effect of link strength is removed would indicate that trophic links are not distributed according to a specific pattern and would be equally distributed between basal species and top ones. On the other hand, the negative correlation found in certain ecosystems indicates that predators would establish more connections than basal species.

Overall, by combining the results obtained for weighted and unweighted webs one can infer that top species would possess same or greater number of trophic links than species feeding lower in the food chain, but most of these connections are weak in magnitude and the skewed link 
a)

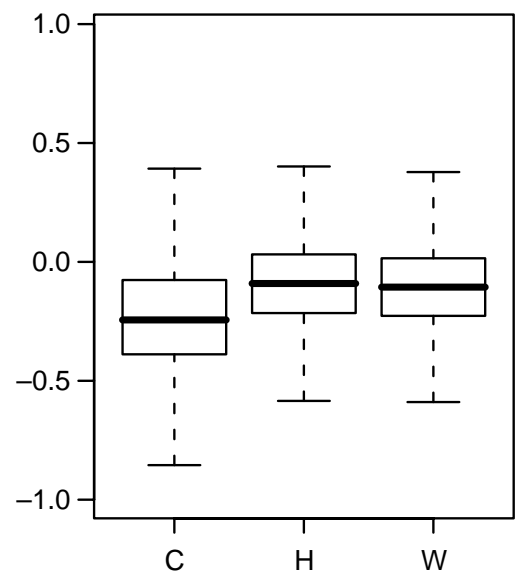

b)

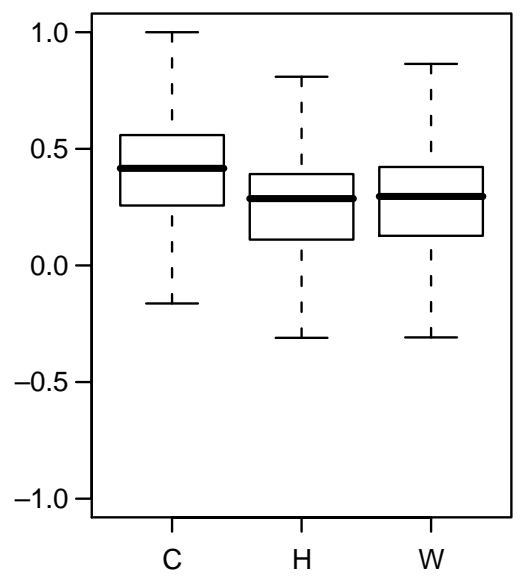

c)

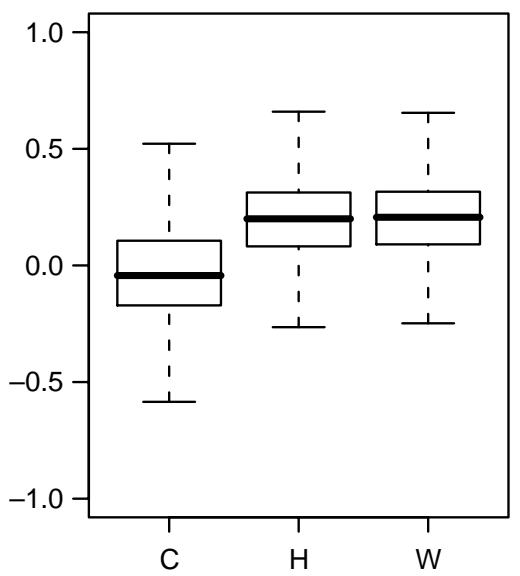

Figure 3. Box plots of Spearman's rho estimating correlations between TP and AMI on inflows $(\mathrm{C}=$ canonical trophic aggregation TP vs 'AMI-living'; $\mathrm{H}=$ original matrix-based TP vs 'AMI-whole'; W = path-based TP vs 'AMI-whole') in simulated networks: (a) binary food webs with same connectance as real ecosystems, randomly distributed links $(\mathrm{C}-$ mean $=-0.211, \mathrm{SD}=0.237 ; \mathrm{H}-$ mean $=-0.098$, $\mathrm{SD}=0.203 ; \mathrm{W}-$ mean $=-0.112, \mathrm{SD}=0.201)$, (b) weighted networks preserving link position as of real webs but randomly assigned intensities $(\mathrm{C}-$ mean $=0.410, \mathrm{SD}=0.195 ; \mathrm{H}-$ mean $=0.263, \mathrm{SD}=0.195 ; \mathrm{W}-$ mean $=0.281, \mathrm{SD}=0.198)$, (c) weighted food webs maintaining same connectance as original ecosystems with link positions and their intensities randomly assigned $(\mathrm{C}-$ mean $=-0.018$, $\mathrm{SD}=0.229 ; \mathrm{H}-$ mean $=0.185, \mathrm{SD}=0.201 ; \mathrm{W}-$ mean $=0.191, \mathrm{SD}=0.198)$.

magnitude would be responsible for lower (weighted) link density of top species in weighted food webs. Moving towards the top of the trophic hierarchy we would encounter fewer stronger links dispersed in many weak links.

There are evidence accumulated in the literature showing that interaction strength follows fat tailed distributions, with most weak links and a few very strong ones (McCann et al. 1998, Sala and Graham 2002, Emmerson and Yearsley 2004). Our results tend to confirm these findings, providing further insight because such skewness seems to be related with the gradient of trophic positions and more pronounced at the top of the trophic hierarchy.

These results have implications for omnivory. Much of the interest about it concerned its degree of occurrence in ecosystem food webs (Yodzis 1984, Williams and Martinez 2004) and the difficulty to accommodate it within the framework of local stability analysis (Pimm and Lawton 1978, Pimm et al. 1991, Fagan 1997). Nonetheless, some studies claimed that omnivory would be more common among taxa at either higher or lower trophic positions. This topic is still controversial. Studies on the Ythan Estuary (Hall and Raffaelli 1991, Raffaelli and Hall 1996) showed that omnivory should be less common for species feeding at lower trophic levels: organisms feeding higher, in fact, having several trophic levels at disposal to feed on, likely would exhibit omnivorous strategies. On the other hand, Yodzis (1984), by studying the 40 Briand's food webs (Briand 1983), argued that the number of loop-forming omnivore links (both observed and expected) decreased as the trophic position of the predators increased. More recently, other studies confirmed that omnivory would predominate above the herbivore trophic level (Thompson et al. 2007). All these works analyzed, however, purely binary food webs. By incorporating interaction strengths in the computation of link density through AMI, we described omnivory as more pronounced toward the bottom of the trophic hierarchy, a result that would have remained hidden if the analysis were carried out using binary food webs.

Simulated models yielded similar results than unweighted binary real webs. When only trophic links are considered (Fig. 3a: C) the correlation between the two indices becomes slightly negative. That is, in binary food webs with randomly distributed links, but maintaining same connectance as the original webs, AMI decreases with trophic position and the number of connections increases for top species. This is what would be predicted by null models. The cascade model (Cohen et al. 1990) predicts food webs characterized by nodes with an increasing number of connections as the trophic position increases (i.e. top predators are more likely to be generalist than lower-ranked species). Also, assemblages of species simulated by the niche model and its variants (Allesina et al. 2008) exhibit more generalist diets as trophic position increases. A possible explanation for our result stands in the inclusion of link magnitude in the analysis. While cascade and niche models are useful to describe topological structure of real ecosystems, the effective specialist activity of species at higher trophic positions, which strongly depends on the uneven distribution of link intensities, might remain hidden due to the use of binary data.

The absence of relation between the Spearman's rho values and the size of the food webs in the six scenarios built up on weighted data suggests for scale independence (correlation between link density and trophic position is not affected by size). Correlations obtained from unweighted trophic networks are also scale-independent, except for the 'living' scenario in which AMI on inflows and TP are based upon trophic links only $\left(R^{2}=0.665, p<<0.001\right)$. This latter result suggests that when using weighted data the effect of food web size vanishes, whereas it affects the correlation between AMI and TP in unweighted webs; this is an important conclusion because it highlights a further diffi- 
culty when food web analysis is carried out on binary data under the living scenario.

In conclusion, to answer our initial questions, the results showed that link density is related to species trophic position and that it decreases from basal species to top consumers; this pattern holds across the ecosystems we studied. Although the concept of trophic level may not be sufficient to explain ecosystem organization, and food web complexity spreads the effects of productivity and consumption throughout the web (Polis and Strong 1996), our results suggest that such activities would be constrained by the trophic hierarchy, which thus becomes a key lecture for energy delivery in food webs. Extending the analysis to the binary counterparts of real food webs and to simulated food webs revealed that the pattern we observed in weighted webs is opposite to that expected from null models. We show here how including interaction strength may change substantially the outcomes of food web analysis and this provides further evidence for a shift in focus from an unweighted to a weighted approach in food web studies (Dunne et al. 2002a, 2002b, Berlow et al. 2004, Tylianakis et al. 2007).

\section{References}

Allesina, S. and Bondavalli, C. 2003. Steady state of ecosystem flow networks: a comparison between balancing procedures. - Ecol. Modell. 165: 221-229.

Allesina, S. et al. 2008. A general model for food web structure. - Science 320: 658-661.

Berlow, E. L. et al. 2004. Interaction strengths in food webs: issues and opportunities. - J. Anim. Ecol. 73: 585-598.

Bersier, L.-F. and Sugihara, G. 1997. Scaling regions for food web properties. - Proc. Natl Acad. Sci. USA 94: 1247-1251.

Bersier, L.-F. and Kehrli, P. 2008. The signature of phylogenetic constraints on food-web structure. - Ecol. Complex. 5: $132-139$.

Bersier, L.-F. et al. 2002. Quantitative descriptors of food-web matrices. - Ecology 83: 2394-2407.

Bondavalli, C. and Ulanowicz, R. E. 1999. Unexpected effects of predators upon their prey: the case of the American alligator. - Ecosystems 2: 49-63.

Briand, F. 1983. Environmental control of food web structure. - Ecology 64: 253-263.

Cattin, M.-F. et al. 2004. Phylogenetic constraints and adaptation explain food web structure. - Nature 427: 835-839.

Christian, R. R. and Luczkovich, J. J. 1999. Organizing and understanding a winter's seagrass foodweb network through effective trophic levels. - Ecol. Modell. 117: 99-124.

Cohen, J. E. et al. 1990. Community food webs: data and theory. - Springer.

Dunne, J. A. et al. 2002a. Food-web structure and network theory: the role of connectance and size. - Proc. Natl Acad. Sci. USA 99: $12917-12922$

Dunne, J. A. et al. 2002b. Network structure and biodiversity loss in food webs: robustness increases with connectance. - Ecol. Lett. 5: 558-567.

Emmerson, M. and Yearsley, J. M. 2004. Weak interactions, omnivory and emergent food-web properties. - Proc. R. Soc. Lond. B 271: 397-405.
Fagan, W. F. 1997. Omnivory as a stabilizing feature of natural communities. - Am. Nat. 150: 554-567.

Hall, S. J. and Raffaelli, D. 1991. Food web patterns: lessons from a species-rich web. - J. Anim. Ecol. 60: 823-842.

Higashi, M. et al. 1989. Food network unfolding: an extension of trophic dynamics for application to natural ecosystems. - J. Theor. Biol. 140: 243-261.

Holt, R. D. and Lawton, J. H. 1994. The ecological consequences of shared natural enemies. - Annu. Rev. Ecol. Syst. 25: 495-520.

Lindeman, R. 1942. The trophic-dynamic aspect of ecology. - Ecology 23: 399-418.

McCann, K. S. et al. 1998. Weak trophic interactions and the balance of nature. - Nature 395: 794-797.

Pimm, S. L. and Lawton, J. H. 1978. On feeding in more than one trophic level. - Nature 254: 542-544.

Pimm, S. L. et al. 1991. Food web patterns and their consequences. - Nature 350: 669-674.

Polis, G. A. and Strong, D. R. 1996. Food web complexity and community dynamics. - Am. Nat. 147: 813-846.

Raffaelli, D. and Hall, S. J. 1996. Assessing the relative importance of trophic links in food webs. - In: Polis, G. A. and Winemiller, K. O. (eds), Food webs: integration of pattern and dynamics. Chapman and Hall, pp. 185-191.

Rossberg, A. G. et al. 2006. Food webs: experts consuming families of experts. - J. Theor. Biol. 241: 552-563.

Rutledge, R. W. et al. 1976. Ecological stability: an information theory viewpoint. - J. Theor. Biol. 57: 355-371.

Sala, E. and Graham, M. H. 2002. Community-wide distribution of predator-prey interaction strength in kelp forests. - Proc. Natl Acad. Sci. USA 99: 3678-3683.

Scotti, M. et al. 2006. Effective trophic positions in ecological acyclic networks. - Ecol. Modell. 198: 495-505.

Thompson, R. M. et al. 2007. Trophic levels and trophic tangles: the prevalence of omnivory in real food webs. - Ecology 88: 612-617.

Tylianakis, J. M. et al. 2007. Habitat modification alters the structure of tropical host-parasitoid food webs. - Nature 455: 202-205.

Ulanowicz, R. E. 1986. Growth and development: ecosystems phenomenology. - Springer.

Ulanowicz, R. E. 2004. Quantitative methods for ecological network analysis. - Comput. Biol. Chem. 28: 321-339.

Ulanowicz, R. E. and Kemp, W. M. 1979. Toward canonical trophic aggregations. - Am. Nat. 114: 871-883.

Ulanowicz, R. E. and Wolff, W. F. 1991. Ecosystem flow networks: loaded dice? - Math. Biosci. 103: 45-68.

van der Zanden, M. J. et al. 1997. Comparing trophic position of freshwater littoral fish species using stable nitrogen isotopes $\left(\delta^{15} \mathrm{~N}\right)$ and literature dietary data. - Can. J. Fish. Aquat. Sci. 54: $1142-1158$.

Whipple, S. J. 1998. Path-based network unfolding: a solution for the problem of mixed trophic and non-trophic processes in trophic dynamic analysis. - J. Theor. Biol. 190: 263-276.

Whipple, S. J. and Patten, B. C. 1993. The problem of nontrophic processes in trophic ecology: toward a network unfolding solution. - J. Theor. Biol. 163: 393-411.

Williams, R. J. and Martinez, N. D. 2000. Simple rules yield complex food webs. - Nature 404: 180-183.

Williams, R. J. and Martinez, N. D. 2004. Limits to trophic levels and omnivory in complex food webs: theory and data. - Am. Nat. 163: 458-468.

Yodzis, P. 1984. How rare is omnivory? - Ecology 65: 321-323. 


\section{Appendix 1.}

\section{Trophic position (TP) and average mutual information (AMI)}

\section{Trophic position}

Trophic position is determined by the type and magnitude of exchange flows. These flows are given in the matrix form that is presented in Fig. $S 1$.

This matrix can be easily partitioned in sub-matrices with flows involving only living components (species or groups of species) and non-living components (receiving non-trophic flows). To apply the canonical trophic aggregation $(\mathrm{C})$ one extracts the sub-matrix of inter-compartmental exchanges between living nodes (Fig. S1), assigning non-living matter and detritus to the first trophic level (Ulanowicz 1995, Scotti et al. 2006). For the original matrixbased network unfolding method (Higashi et al. 1989) and the path-based network unfolding analysis (Whipple 1998) the whole set of flows in the matrix is considered (decyclization algorithms are not required) and this prevent detritus from being assigned an arbitrary trophic level (Fig. S1).

In $\mathrm{C}$, TP calculation is performed as in Eq. S1. In case of a binary food web the trophic activity would be evenly distributed between the prey (Eq. S2).

$$
\begin{aligned}
& \mathrm{TP}_{\mathrm{j}}=1+\sum_{\mathrm{i}=1}^{s} \mathrm{TP}_{\mathrm{i}} \times \frac{\mathrm{t}_{\mathrm{ij}}}{\mathrm{T}_{\mathrm{j}}} \\
& \mathrm{TP}_{\mathrm{j}}=1+\sum_{\mathrm{i}=1}^{s} \mathrm{TP}_{\mathrm{i}} \times \frac{\mathrm{l}_{\mathrm{ij}}}{\mathrm{n}_{\mathrm{j} j}}
\end{aligned}
$$

$\mathrm{S}$ is the total number of nodes, $\mathrm{TP}_{\mathrm{i}}$ and $\mathrm{TP}_{\mathrm{i}}$ are, respectively, the trophic positions of nodes $i$ and $j$, while the ratio between $t_{i j}$ and $T_{i}$ is the fraction by which species $i\left(t_{i j}\right)$ enters the diet of species $j\left(T_{. j}\right)$.

The calculation for binary data makes use of $n_{. j}$, the total number of links entering the species $j$, and $l_{i j}$ that is 1 if species $j$ consumes species $i$ and 0 if not. The diet composition of each species can be inferred by evenly assigning the whole intake among its prey, in case of unweighted food webs, or proportionally distributing the total input according to the strength of trophic links. So, if a species is partially primary carnivore for half of its energy intake, and herbivore for the remaining half, calculation yields a TP of 2.5 $=0.5 \times 2+0.5 \times 3$.

\section{Average mutual information (AMI)}

The question whether complexity affects ecosystem stability has long been central in ecology. MacArthur (1955) applied Shannon's information index to the flows in ecosystem networks as

$$
\mathrm{H}=-\mathrm{k} \sum_{\mathrm{i}=1}^{s} \sum_{\mathrm{j}=1}^{s} \frac{\mathrm{t}_{\mathrm{ij}}}{\mathrm{T}} \log _{2}\left(\frac{\mathrm{t}_{\mathrm{ij}}}{\mathrm{T}}\right)
$$

where $\mathrm{H}$ and $\mathrm{S}$ are the diversity of flows and the number of species in the network, respectively; $\mathrm{k}$ is a scalar constant, and $\mathrm{t}_{\mathrm{ij}}$ is the flow

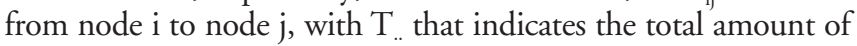
energy throughout the network (total system throughput, TST)

$$
\operatorname{TST}=\sum_{\mathrm{i}=1}^{\mathrm{s}} \sum_{\mathrm{j}=1}^{\mathrm{s}} \mathrm{t}_{\mathrm{ij}}=\mathrm{T}
$$

The increasing consensus around this index stimulated its application to the more accessible stocks of biomass, shifting the discussion from flow diversity to biomass diversity and its effects on stability. Unfortunately, May (1972) demonstrated that a higher biodiversity in linear dynamical systems was more likely to result in instability and ecologists quickly abandoned applications of information theory to food webs, maintaining the same prejudice also when Rutledge et al. (1976) applied a Bayesian emendation of Shannon's measure to MacArthur's index of flow diversity. These authors used the notion of conditional probability and split MacArthur's index in two complementary terms. The joint probability that an arbitrary elementary unit of currency both leaves i and enters $j$ can be estimated by the quotient $\left(t_{i j} / T_{.}\right)$, whereas the conditional probability that the unit goes to compartment $\mathrm{j}$, given it already left $\mathrm{i}\left(\mathrm{T}_{\mathrm{i}}\right)$, or that exhibited by a flow exiting the node $\mathrm{i}$ in respect to the total input to compartment $\mathrm{j}\left(\mathrm{T}_{\mathrm{j}}\right)$ are defined, respectively, as

$$
\frac{t_{i j}}{\sum_{z=1}^{s} t_{i z}}=\frac{t_{i j}}{T_{i}} .
$$

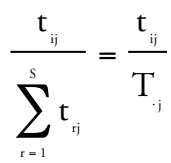

As a consequence, the measure of total flow diversity is amended as follows

$\mathrm{H}=\mathrm{AMI}+\mathrm{H}_{c}$

where the average mutual information (AMI) quantifies the amount of diversity that is encumbered by structural constraints

AMI $=k \sum_{\mathrm{i}=1}^{s} \sum_{\mathrm{j}=1}^{s} \frac{\mathrm{t}_{\mathrm{ij}}}{\mathrm{T}_{.}} \log _{2}\left(\frac{\mathrm{t}_{\mathrm{ij}} \mathrm{T}_{\ldots}}{\mathrm{T}_{\mathrm{i}, \mathrm{T}_{\mathrm{j}}}}\right)$ 
and $H_{c}$ represents the amount of 'choice' (residual diversity/freedom) pertaining to both the inputs and outputs of an average node in the network.

$$
\mathrm{H}_{\mathrm{c}}=-\mathrm{k} \sum_{\mathrm{i}=1}^{\mathrm{s}} \sum_{\mathrm{j}=1}^{\mathrm{s}} \frac{\mathrm{t}_{\mathrm{ij}}}{\mathrm{T}} \log _{2}\left(\frac{\mathrm{t}_{\mathrm{ij}}^{2}}{\mathrm{~T}_{\mathrm{i},} \mathrm{T}_{\mathrm{j} j}}\right)
$$

Therefore, the overall complexity of the flow structure, as measured by the MacArthur's index, can be divided in two parts: a) AMI that estimates how orderly and coherently flows are connected; b) $\mathrm{H}_{c}$ that gauges the disorder and freedom that is preserved. Rutledge et al. (1976) proposed $\mathrm{H}_{\mathrm{c}}$ as an appropriate measure of ecosystem maturity (Odum 1969), but further studies (Atlan 1974, Ulanowicz 1980) suggested AMI as more reliable index to describe the developmental status of an ecological network. However, Ulanowicz and Wolff (1991) adopted $\mathrm{H}_{\mathrm{c}}$ as a tool to estimate effective connectance per node in ecosystems. In particular, dividing $\mathrm{H}_{\mathrm{c}}$ in two terms reveals more about its meaning:

$$
\begin{aligned}
& \mathrm{H}_{\mathrm{c}}=-\sum_{\mathrm{i}=1}^{s} \sum_{\mathrm{j}=1}^{\mathrm{s}} \frac{\mathrm{t}_{\mathrm{ij}}}{\mathrm{T}_{\ldots}} \log _{2}\left(\frac{\mathrm{t}_{\mathrm{ij}}}{\mathrm{T}_{\mathrm{i}}}\right)-\sum_{\mathrm{i}=1}^{\mathrm{s}} \sum_{\mathrm{j}=1}^{\mathrm{s}} \frac{\mathrm{t}_{\mathrm{ij}}}{\mathrm{T}_{\ldots}} \log _{2}\left(\frac{\mathrm{t}_{\mathrm{ij}}}{\mathrm{T}_{\mathrm{j}}}\right)= \\
& =\sum_{\mathrm{i}=1}^{s} \frac{\mathrm{T}_{\mathrm{i}}}{\mathrm{T}_{i}}\left[-\sum_{\mathrm{j}=1}^{\mathrm{s}} \frac{\mathrm{t}_{\mathrm{ij}}}{\mathrm{T}_{\mathrm{i}}} \log _{2}\left(\frac{\mathrm{t}_{\mathrm{ij}}}{\mathrm{T}_{\mathrm{i}}}\right)\right]+\sum_{\mathrm{j}=1}^{\mathrm{s}} \frac{\mathrm{T}_{\cdot \mathrm{j}}}{\mathrm{T}_{i}}\left[-\sum_{\mathrm{i}=1}^{\mathrm{s}} \frac{\mathrm{t}_{\mathrm{ij}}}{\mathrm{T}_{\mathrm{j}}} \log _{2}\left(\frac{\mathrm{t}_{\mathrm{ij}}}{\mathrm{T}_{\cdot \mathrm{j}}}\right)\right]= \\
& =\sum_{i=1}^{s} \frac{T_{i} \cdot}{T} H_{i}+\sum_{j=1}^{s} \frac{T_{\cdot j}}{T} H_{i j}
\end{aligned}
$$

with output diversity at node $\mathrm{i}\left(\mathrm{H}_{\mathrm{i}}\right)$ and input diversity at node $\mathrm{j}$ $\left(\mathrm{H}_{. j}\right)$ calculated as

$$
H_{i}=-\sum_{j=1}^{s} \frac{t_{i j}}{T_{i}} \log _{2}\left(\frac{t_{i j}}{T_{i}}\right)
$$

and

$$
H_{\cdot j}=-\sum_{i=1}^{s} \frac{t_{i j}}{T_{. j}} \log _{2}\left(\frac{t_{i j}}{T_{. j}}\right)
$$

Average diversity of the biomass going to consumers, weighted by total outputs $\left(\mathrm{T}_{\mathrm{i}}\right)$, and average diversity of inflows, weighted by total inputs $\left(\mathrm{T}_{. j}\right)$, constitute Eq. S10, with the average diversity over both input and output that can be written as $\mathrm{H}_{c} / 2$. Because the diversity of pathways through a decision tree is an exponential function of the number of branch points that generate the tree, the mean number of flows from a typical node in the network should be

$$
\mathrm{m}=2^{\mathrm{H}^{12}}
$$

Similarly to what proposed by Ulanowicz and Wolff (1991), Bersier et al. (2002) applied the diversity of input and output biomass flows to compute a sort of effective connectance index called link density (LD). First, they introduced the equivalent numbers of consumers for taxon $\mathrm{i}\left(\mathrm{n}_{\mathrm{i}}\right)$ and prey for taxon $\mathrm{j}\left(\mathrm{n}_{\mathrm{j}}\right)$, computed as the reciprocals of $\mathrm{H}_{\mathrm{i}}$ and $\mathrm{H}_{\text {. }}$

$$
\mathrm{n}_{\mathrm{i} .}= \begin{cases}2^{\mathrm{H}_{\mathrm{i}}} & \\ 0 & \text { if } \mathrm{T}_{\mathrm{i} .}=0\end{cases}
$$

$\mathrm{n}_{\cdot j}=\left\{\begin{array}{l}2^{\mathrm{H} \cdot j} \\ 0 \quad \text { if } \mathrm{T}_{\cdot j}=0\end{array}\right.$

Equivalent numbers of consumers and prey represent the number of events that, occurring in equal proportion, would produce the same values of outflow and inflow diversity measured in a given ecosystem. The link density is then computed averaging equivalent numbers of consumers and prey over all the species and weighting their values by relative outflows and inflows

$L D=\frac{1}{2}\left(\sum_{i=1}^{S} \frac{T_{i \cdot}}{T_{. .}} 2^{H_{i \cdot}}+\sum_{j=1}^{S} \frac{T_{\cdot j}}{T_{\ldots}} 2^{H_{j i}}\right)$

Then, the difference between the effective connectance $(\mathrm{m})$ proposed by Ulanowicz and Wolff (1991) and the link density (LD) formulated by Bersier et al. (2002) resides solely in the weighting which applies, in the first case, to outflow and inflow diversities, and to taxa's equivalent numbers of consumers and prey in the latter. In particular, the effect of weighting is larger when $\mathrm{m}$ is computed, being applied to diversities as exponents in the geometric mean of input and output effective connectance.

Both the applications developed by Ulanowicz and Wolff (1991) and Bersier et al. (2002) are obtained from output (Eq. S11) and input (Eq. S12) diversities, aiming to identify average connectance per node. In particular, they refer to the Eq. S9, making use of information on residual diversity $\left(\mathrm{H}_{\mathrm{c}}\right)$ for total equivalent links (both entering and exiting each node).

In the present manuscript we discuss an alternative approach, focusing on average mutual information (Eq. S8) which accounts for constraints in the flow structure. We split the whole index into relative contribution of flows entering or exiting each node, weighting their effect with the corresponding throughput $\left(\mathrm{T}_{. j}\right.$ or $\mathrm{T}_{\mathrm{i}}$ )

$$
\begin{aligned}
& \operatorname{AMI}_{\cdot j}=\frac{1}{T_{i j}}\left[\sum_{i=1}^{s} t_{i j} \log _{2}\left(\frac{t_{i j} T_{.}}{T_{i,} T_{j, j}}\right)\right]
\end{aligned}
$$

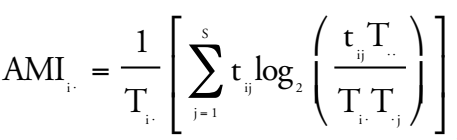

The information is correlated both to the level of input flow articulation, for each node $\mathrm{j}$, and to outflow diversity of $\mathrm{i}$ prey when the AMI on incoming links is estimated (Eq. S17), while adopting its counterpart on outgoing links, evenness of flows exiting each node $i$ and entering its predators $j$ is measured (Eq. S18).

A generalist trophic behavior, meaning more indeterminacy of flow structure, is described by a lower AMI on inflows (AMI.j) than in case of specialized diets, while the tendency to avoid sharing natural enemies (apparent competition) with similar species, represented by peculiar pathways linking a prey to its predators, is associated to higher AMI on outflows $\left(\mathrm{AMI}_{\mathrm{i}}\right.$ ).

Since the catalyst for the formulation of AMI on inflows and outflows is the Shannon measure of entropy (Shannon 1948), these indices reach their minimum when all the input flows to node $\mathrm{j}$, or output links from compartment $\mathrm{i}$, occur in equal intensity, while the maximum is a function of the energy/matter distribution in each event. Moreover, their contribution to the whole AMI depends on the fraction of throughput processed by each node $\mathrm{j}\left(\mathrm{T}_{. \mathrm{j}}\right)$, or $\mathrm{i}\left(\mathrm{T}_{\mathrm{i}}\right)$, as regards to TST $\left(\mathrm{T}_{.}\right)$ 


$$
\begin{aligned}
& \mathrm{AMI}=\sum_{j=1}^{s} \frac{\mathrm{T}_{\cdot j}}{\mathrm{~T}} \mathrm{AMI}_{\cdot j}= \\
& =\sum_{\mathrm{j}=1}^{s} \frac{\mathrm{T}_{\cdot j}}{\mathrm{~T}_{. .}} \frac{1}{\mathrm{~T}_{. j}}\left[\sum_{\mathrm{i}=1}^{s} \mathrm{t}_{\mathrm{ij}} \log _{2}\left(\frac{\mathrm{t}_{\mathrm{ij}} \mathrm{T}_{. .}}{\mathrm{T}_{\mathrm{i},} \mathrm{T}_{\cdot \mathrm{j}}}\right)\right]= \\
& =\sum_{\mathrm{i}=1}^{\mathrm{s}} \sum_{\mathrm{j}=1}^{\mathrm{s}} \frac{\mathrm{t}_{\mathrm{ij}}}{\mathrm{T}_{\ldots}} \log _{2}\left(\frac{\mathrm{t}_{\mathrm{ij}} \mathrm{T}_{\ldots}}{\mathrm{T}_{\mathrm{i},} \mathrm{T}_{\mathrm{j} j}}\right)
\end{aligned}
$$

$$
\begin{aligned}
& \mathrm{AMI}=\sum_{\mathrm{i}=1}^{\mathrm{s}} \frac{\mathrm{T}_{\mathrm{i}}}{\mathrm{T}} \mathrm{AMI}_{\mathrm{i} \cdot}= \\
& =\sum_{\mathrm{i}=1}^{\mathrm{s}} \frac{\mathrm{T}_{\mathrm{i}}}{\mathrm{T}_{\ldots}} \frac{1}{\mathrm{~T}_{\mathrm{i}}}\left[\sum_{\mathrm{i}=1}^{\mathrm{s}} \mathrm{t}_{\mathrm{ij}} \log _{2}\left(\frac{\mathrm{t}_{\mathrm{ij}} \mathrm{T}_{.}}{\mathrm{T}_{\mathrm{i} \cdot} \mathrm{T}_{\cdot \mathrm{j}}}\right)\right]= \\
& =\sum_{\mathrm{i}=1}^{\mathrm{s}} \sum_{\mathrm{j}=1}^{\mathrm{s}} \frac{\mathrm{t}_{\mathrm{ij}}}{\mathrm{T}_{\text {. }}} \log _{2}\left(\frac{\mathrm{t}_{\mathrm{ij}} \mathrm{T}_{\mathrm{.}}}{\mathrm{T}_{\mathrm{i} \cdot} \mathrm{T}_{\cdot \mathrm{j}}}\right)
\end{aligned}
$$

\section{References}

Almunia, J. et al. 1999. Benthic-pelagic switching in a coastal subtropical lagoon. - Estuarine Coastal Shelf Sci. 49: 363-384.

Atlan, H. 1974. On a formal definition of organization. - J. Theor. Biol. 45: 295-304.

Baird, D. and Milne, H. 1981. Energy flow in the Ythan Estuary, Aberdeenshire, Scotland. - Estuarine Coastal Shelf Sci. 13: 455-472.

Baird, D. and Ulanowicz, R. E. 1989. The seasonal dynamics of the Chesapeake Bay ecosystem. - Ecol. Monogr. 59: 329-364.

Baird, D. et al. 1998. Assessment of spatial and temporal variability in ecosystem attributes of the St Marks National Wildlife Refuge, Apalachee Bay, Florida. - Estuarine Coastal Shelf Sci. 47: 329-349.

Bersier, L.-F. et al. 2002. Quantitative descriptors of food-web matrices. - Ecology 83: 2394-2407.

Hagy, J. D. 2002. Eutrophication, hypoxia and trophic transfer efficiency in Chesapeake Bay. PhD thesis. - Univ. of Maryland at College Park.

Higashi, M. et al. 1989. Food network unfolding - an extension of trophic dynamics for application to natural ecosystems. - J. Theor. Biol. 140: $243-261$.

Lindeman, R. 1942. The trophic-dynamic aspect of ecology. - Ecology 23: 399-418.
MacArthur, R. H. 1955. Fluctuations of animal populations and a measure of community stability. - Ecology 36: 533-536.

May, R. M. 1972. Will a large complex system be stable? - Nature 238: 413-414.

Monaco, M. E. and Ulanowicz, R. E. 1997. Comparative ecosystem trophic structure of three US mid-Atlantic estuaries. - Mar. Ecol. Prog. Ser. 161: 239-254.

Odum, E. 1969. The strategy of ecosystem development. - Science 164: 262-270.

Patrício, J. et al. 2004. Ascendency as an ecological indicator: a case study of estuarine pulse eutrophication. - Estuarine Coastal Shelf Sci. 60: 23-35.

Rutledge, R. W. et al. 1976. Ecological stability: an information theory viewpoint. - J. Theor. Biol. 57: 355-371.

Scotti, M. et al. 2006. Effective trophic positions in ecological acyclic networks. - Ecol. Modell. 198: 495-505.

Shannon, C. E. 1948. A mathematical theory of communications. - Bell System Tech. J. 27: 379-423.

Steele, J. H. 1974. The structure of marine ecosystems. - Harvard Univ. Press.

Ulanowicz, R. E. 1980. An hypothesis on the development of natural communities. - J. Theor. Biol. 85: 223-245.

Ulanowicz, R. E. 1986. Growth and development: ecosystems phenomenology. - Springer.

Ulanowicz, R. E. 1995. Ecosystem trophic foundations: Lindeman exonerata. - In: Patten, B. C. and Jorgensen, S. E. (eds), Complex ecology: the part-whole relation in ecosystems. Prentice-Hall, pp. 549-560.

Ulanowicz, R. E. and Wolff, W. F. 1991. Ecosystem flow networks: loaded dice? - Math. Biosci. 103: 45-68.

Ulanowicz, R. E. et al. 1997. Network analysis of trophic dynamics in south Florida ecosystems, FY 96: The Cypress Wetland ecosystem. - Tech. Rep. [UMCES] CBL 97-075, Chesapeake Biol. Lab., Solomons.

Ulanowicz, R. E. et al. 1998. Network analysis of trophic dynamics in south Florida ecosystems, FY 97: The Florida Bay ecosystem. - Tech. Rep. [UMCES] CBL 98-123, Chesapeake Biol. Lab., Solomons.

Ulanowicz, R. E. et al. 1999. Network analysis of trophic dynamics in south Florida ecosystem, FY 98: the mangrove ecosystem. - Tech. Rep. [UMCES] CBL 99-0073, Chesapeake Biol. Lab., Solomons.

Ulanowicz, R. E. et al. 2000. Network analysis of trophic dynamics in south Florida ecosystems FY 99: the graminoid ecosystem. - Tech. Rep. [UMCES] CBL 00-0176, Chesapeake Biol. Lab., Solomons.

Whipple, S. J. 1998. Path-based network unfolding: a solution for the problem of mixed trophic and non-trophic processes in trophic dynamic analysis. - J. Theor. Biol. 190: 263-276.

Wulff, F. and Ulanowicz, R. E. 1989. A comparative anatomy of the Baltic Sea and Chesapeake Bay ecosystems. - In: Wulff, F. et al. (eds), Network analysis in marine ecology: methods and applications. Vol. 32 of Coastal and Estuarine Studies. Springer. 


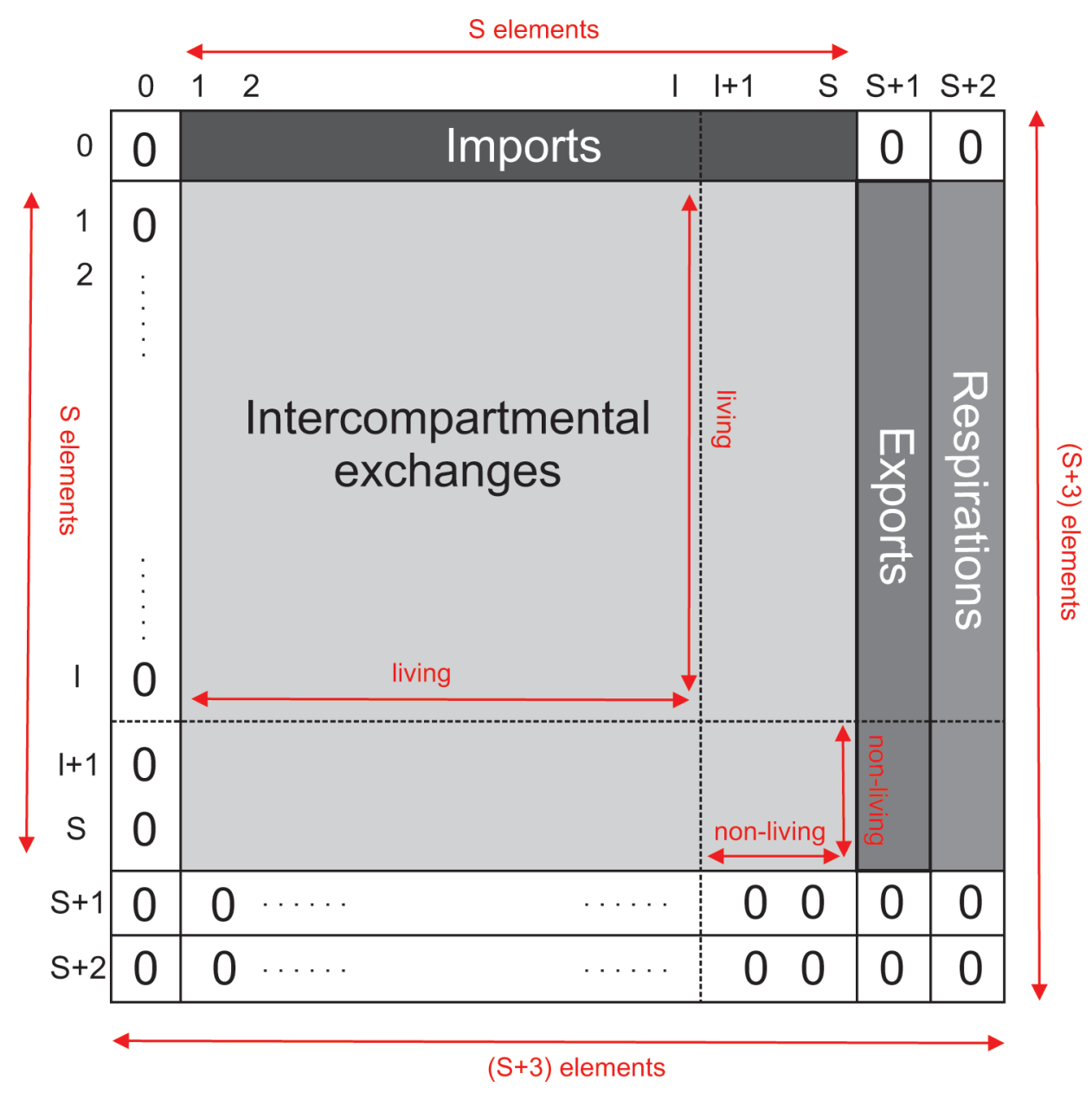

Figure $S 1$. A squared $(S+3) \times(S+3)$ matrix is another form to represent ecological flow networks. It is comprised of exchange flows between system compartments (l living and nl non-living) and the outside environment. Flows from and to the outside environment are called imports, exports and respirations (non-usable energy). Food webs, in this work, originated from ecological flow networks and link intensities were determined by flow values of the corresponding network matrices. 
a)

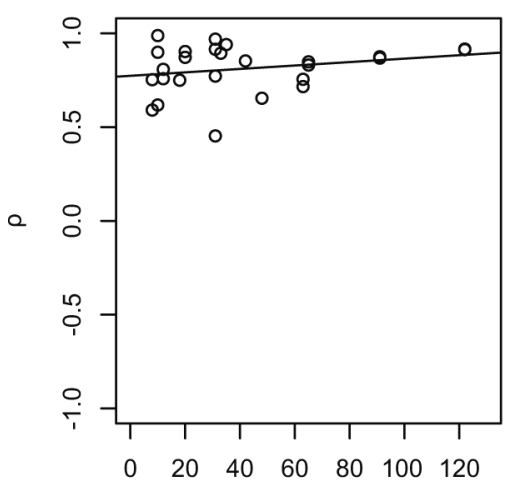

S

d)

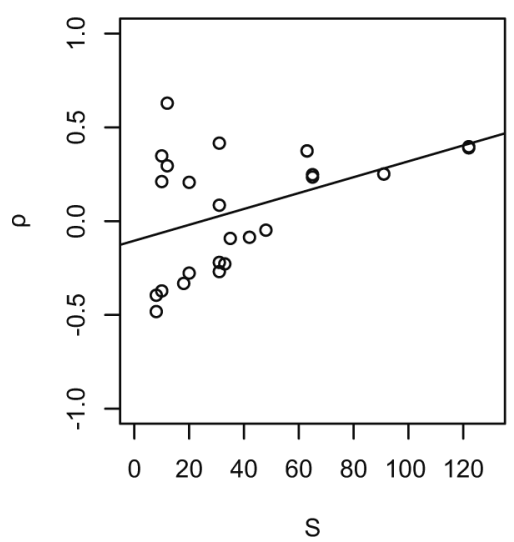

b)

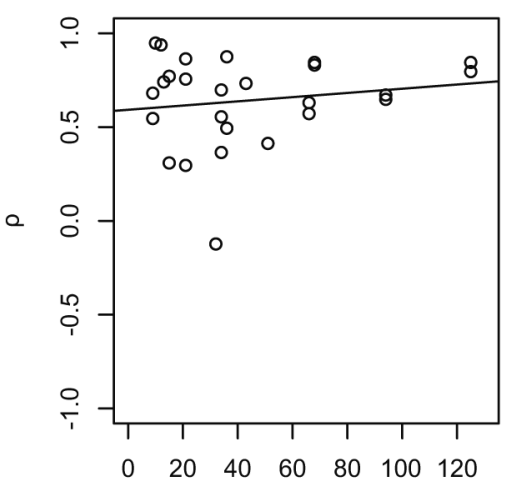

S

e)

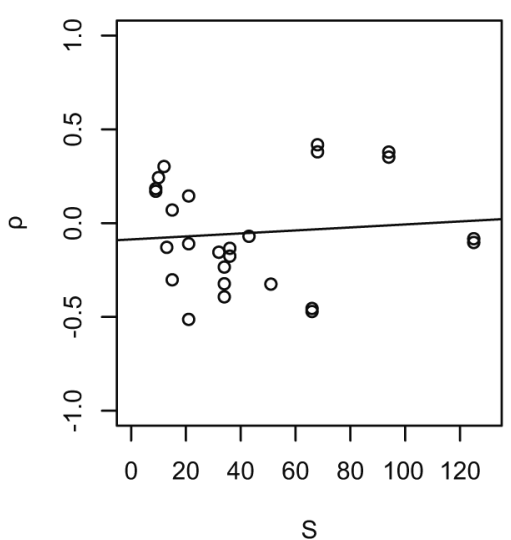

c)

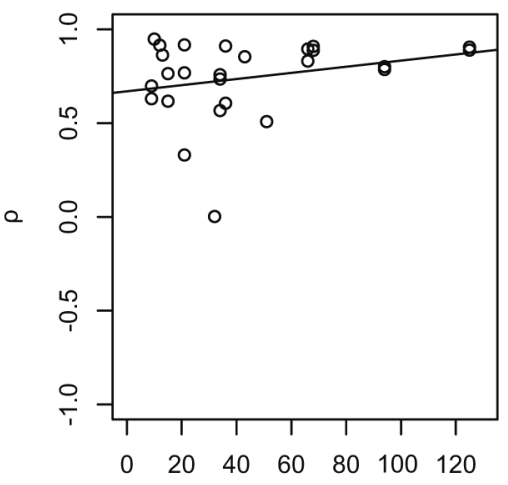

S

f)

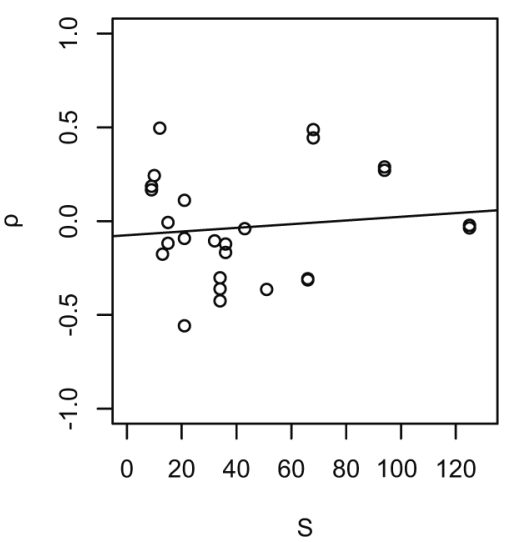

Figure S2. Plots of Spearman's rho values against food web size in presence of weighted data. Plots (a), (b) and (c) refer to the Input scenario (AMI computed on incoming links). Plots (d), (e) and (f) refer to the Output scenario (AMI on outflows). In plots (a) and (d) correlation coefficients are based on AMI vs C; correlation coefficients that make plots (b) and (e) are based on AMI vs H; finally, Spearman's rho values in plots $(\mathrm{c})$ and (f) were computed as AMI vs W. Linear regression lines are shown $(S=$ number of compartments) 
a)

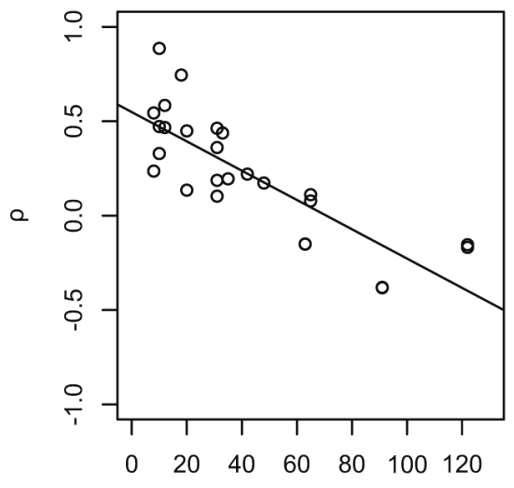

$\mathrm{s}$

d)

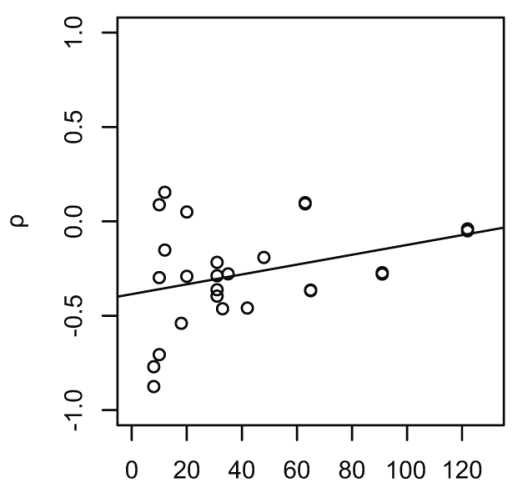

S b)

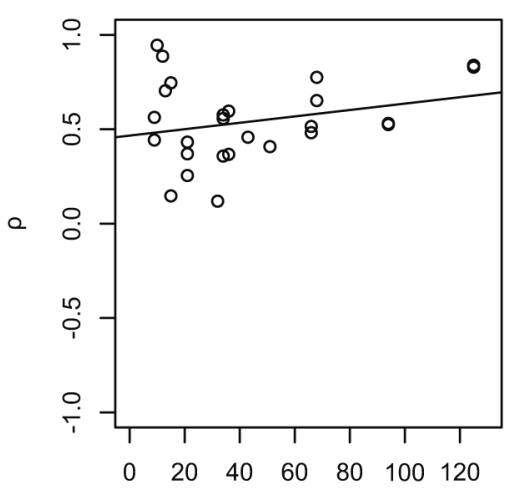

$\mathrm{S}$

e)

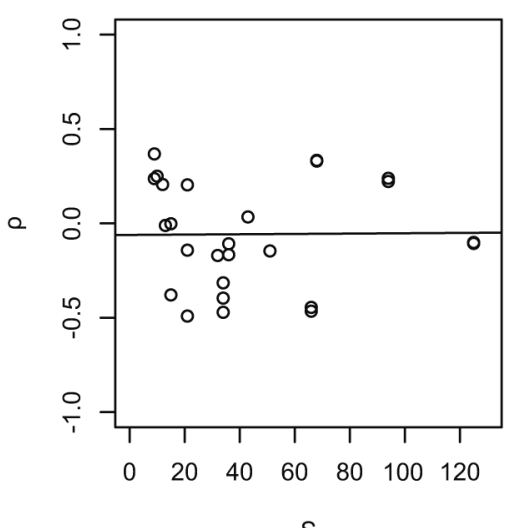

c)

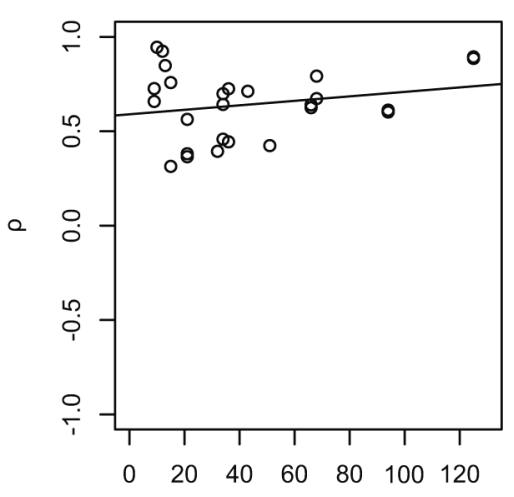

S

f)

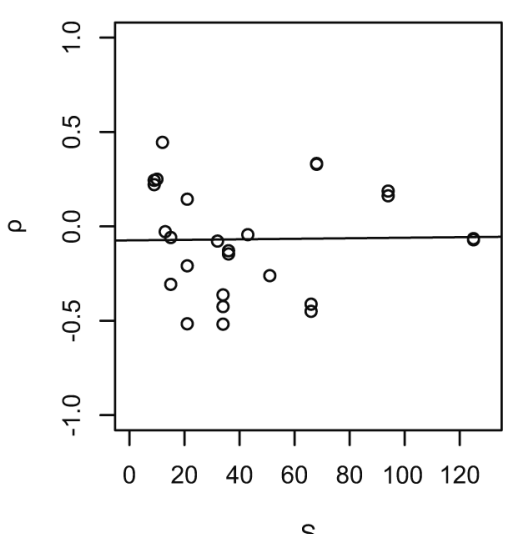

Figure S3. Effect of network size ( $\mathrm{S}$ = number of compartments) on the correlations between AMI and TP in the 26 binary food webs. The keys for plots are the same as in Fig. S2. All the correlations are scale-independent but the first case, when strictly living exchanges are considered in the comparison between AMI on incoming links and TP $\left(\mathrm{R}^{2}=0.665, \mathrm{p}<<0.001\right)$. Linear regression lines are depicted. 
Table S1. List of the ecological networks considered in the analysis. Total number of nodes (S) and number of non-living compartments

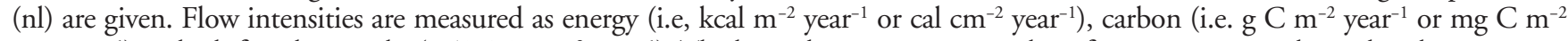
summer ${ }^{-1}$ ) and ash free dry weight $\left(\mathrm{g} \mathrm{AFDW} \mathrm{m}^{-2}\right.$ year $\left.^{-1}\right)$. The last column summarizes the references to networks analyzed.

\begin{tabular}{|c|c|c|c|c|}
\hline Ecosystems & $S$ & $\mathrm{nl}$ & Flow units & References \\
\hline \multicolumn{5}{|l|}{ NETWRK } \\
\hline Aggregated Baltic Sea & 15 & 3 & $\mathrm{mg} \mathrm{C} \mathrm{m} \mathrm{m}^{-2} \mathrm{day}^{-1}$ & Wulff and Ulanowicz 1989 \\
\hline Cedar Bog Lake & 9 & 1 & $\mathrm{cal} \mathrm{cm}^{-2}$ year $^{-1}$ & Lindeman 1942 \\
\hline Charca de Maspalomas & 21 & 3 & $\mathrm{mg} \mathrm{C} \mathrm{m}{ }^{-2}$ day $^{-1}$ & Almunia et al. 1999 \\
\hline Chesapeake Mesohaline Ecosystem & 15 & 3 & $\mathrm{mg} \mathrm{C} \mathrm{m} \mathrm{m}^{-2} \mathrm{day}^{-1}$ & Wulff and Ulanowicz 1989 \\
\hline Chesapeake Mesohaline Network & 36 & 3 & $\mathrm{mg} \mathrm{C} \mathrm{m}^{-2}$ summer $^{-1}$ & Baird and Ulanowicz 1989 \\
\hline Crystal River Creek (control) & 21 & 1 & 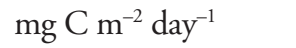 & M. Homer W. M. and Kemp unpubl., Ulanowicz 1986 \\
\hline Crystal River Creek (delta temp.) & 21 & 1 & 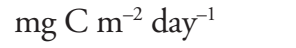 & M. Homer W. M. and Kemp unpubl., Ulanowicz 1986 \\
\hline Lower Chesapeake Bay in Summer & 34 & 3 & $\mathrm{mg} \mathrm{C} \mathrm{m}^{-2}$ summer $^{-1}$ & Hagy 2002 \\
\hline St. Marks River (Florida) Flow Network & 51 & 3 & $\mathrm{mg} \mathrm{C} \mathrm{m} \mathrm{m}^{-2} \mathrm{day}^{-1}$ & Baird et al. 1998 \\
\hline Lake Michigan Control Network & 36 & 1 & $\mathrm{~g} \mathrm{C} \mathrm{m}^{-2}$ year $^{-1}$ & A. E. Krause and D. M. Mason unpubl. \\
\hline Middle Chesapeake Bay in Summer & 34 & 3 & $\mathrm{mg} \mathrm{C} \mathrm{m}^{-2}$ summer $^{-1}$ & Hagy 2002 \\
\hline Mondego Estuary & 43 & 1 & g AFDW m $^{-2}$ year $^{-1}$ & Patrício et al. 2004 \\
\hline Final Narraganasett Bay Model & 32 & 1 & $\mathrm{mg} \mathrm{C} \mathrm{m}^{-2}$ year $^{-1}$ & Monaco and Ulanowicz 1997 \\
\hline North Sea & 10 & 0 & $\mathrm{kcal} \mathrm{m}^{-2}$ year $^{-1}$ & Steele 1974 \\
\hline Somme Estuary & 9 & 1 & $\mathrm{~g} \mathrm{C} \mathrm{m}^{-2}$ year $^{-1}$ & H. Rybarczyk unpubl. \\
\hline Upper Chesapeake Bay in Summer & 34 & 3 & $\mathrm{mg} \mathrm{C} \mathrm{m}^{-2}$ summer $^{-1}$ & Hagy 2002 \\
\hline Upper Chesapeake Bay & 12 & 2 & $\mathrm{~g} \mathrm{C} \mathrm{m}^{-2}$ year $^{-1}$ & A. Osgood unpubl. \\
\hline Ythan Estuary & 13 & 3 & $\mathrm{~g} \mathrm{C} \mathrm{m}^{-2}$ year $^{-1}$ & Baird and Milne 1981 \\
\hline \multicolumn{5}{|l|}{ ATLSS } \\
\hline Cypress Wetlands (dry season) & 68 & 3 & $\mathrm{~g} \mathrm{C} \mathrm{m}^{-2}$ year $^{-1}$ & Ulanowicz et al. 1997 \\
\hline Cypress Wetlands (wet season) & 68 & 3 & $\mathrm{~g} \mathrm{C} \mathrm{m}^{-2}$ year $^{-1}$ & Ulanowicz et al. 1997 \\
\hline Marshes and Sloughs (dry season) & 66 & 3 & $\mathrm{~g} \mathrm{C} \mathrm{m}^{-2}$ year $^{-1}$ & Ulanowicz et al. 2000 \\
\hline Marshes and Sloughs (wet season) & 66 & 3 & $\mathrm{~g} \mathrm{C} \mathrm{m}^{-2}$ year $^{-1}$ & Ulanowicz et al. 2000 \\
\hline Florida Bay (dry season) & 125 & 3 & $\mathrm{~g} \mathrm{C} \mathrm{m}^{-2}$ year $^{-1}$ & Ulanowicz et al. 1998 \\
\hline Florida Bay (wet season) & 125 & 3 & $\mathrm{~g} \mathrm{C} \mathrm{m}^{-2}$ year $^{-1}$ & Ulanowicz et al. 1998 \\
\hline Mangroves (dry season) & 94 & 3 & $\mathrm{~g} \mathrm{C} \mathrm{m}^{-2}$ year $^{-1}$ & Ulanowicz et al. 1999 \\
\hline Mangroves (wet season) & 94 & 3 & $\mathrm{~g} \mathrm{C} \mathrm{m}^{-2}$ year $^{-1}$ & Ulanowicz et al. 1999 \\
\hline
\end{tabular}

